\title{
EFECTO DE LACTOFERRINA BOVINA EN LA FORMACIÓN DE BIOFILMS EN CEPAS CLÍNICAS DE E. coli ENTEROAGREGATIVA
}

\author{
Cecilia Coveñas $^{1, a}$, Georgette Dextre $^{1, a}$, Diana Fernandez ${ }^{1, a}$, Susan Mosquito ${ }^{1, b}$, Theresa Ochoa ${ }^{1,2, c}$
}

\begin{abstract}
RESUMEN
Objetivos. Determinar el efecto de lactoferrina bovina (bLf) en la formación de biofilms en cepas clínicas de Escherichia coli enteroagregativa (EAEC), y si este efecto es independiente del hierro. Materiales y métodos. Se utilizaron dos métodos: (a) cualitativo, mediante observación directa por microscopia óptica, y (b) cuantitativo, lecturas de los valores de absorbancia mediante lector de ELISA en presencia de bLf en concentraciones de $0,01 \mathrm{mg} / \mathrm{mL}$ y $1 \mathrm{mg} / \mathrm{mL}$, con y sin hierro, y no bLf (control), en 122 cepas de EAEC para el método cuantitativo (60 cepas de niños con diarrea y 62 de niños sanos) y 31 cepas para el método cualitativo. Resultados. (a) Método cualitativo: se evaluaron 31 cepas, con y sin hierro. Sin hierro la formación de biofilms fue de $77 \%$ (24/31) en el grupo control versus 58\% (14/31) con bLf de $0,01 \mathrm{mg} / \mathrm{mL}$ y $4 \%(1 / 31)$ con $1 \mathrm{mg} / \mathrm{mL}$. Con hierro la formación de biofilms fue $90 \%(28 / 31)$ en el grupo control versus $55 \%(17 / 31)$ con bLf de $0,01 \mathrm{mg} / \mathrm{mL}$ y $4 \%(1 / 31)$ a $1 \mathrm{mg} / \mathrm{mL}$. (b) Método cuantitativo: sin hierro la absorbancia medida a OD $560 \mathrm{~nm}$ del grupo control fue $0,7 \pm 0,5$ versus $0,4 \pm 0,3$ con bLf $0,01 \mathrm{mg} / \mathrm{mL}$ y $0,3 \pm 0,2 \mathrm{con}$ bLf de $1 \mathrm{mg} / \mathrm{mL}(p<0,0001)$. Esta disminución en presencia de bLf incluso se dio con hierro. Conclusiones. La bLf tiende a disminuir la formación de biofilms, mostrando un efecto inhibitorio en las cepas clínicas de EAEC, este efecto no es hierro-dependiente.
\end{abstract}

Palabras clave: Lactoferrina; Escherichia coli enteroagregativa; Biofilmes (fuente: DeCS/BIREME).

\section{EFFECT OF BOVINE LACTOFERRIN BIOFILMS IN THE FORMATION OF CLINICAL STRAINS OF ENTEROAGGREGATIVE E. Coli}

\begin{abstract}
Objectives. To determine the effect of bovine lactoferrin (BLF) in the formation of biofilms in clinical enteroaggregative Escherichia coli (EAEC) strains and whether this effect is independent of iron. Materials and methods. Two methods were used: (a) qualitative, by direct observation of optical microscopy, and (b) quantitative readings of the absorbance values using ELISA reader in the presence of bLf in concentrations of $0.01 \mathrm{mg} \mathrm{mL}$ and $1 \mathrm{mg} / \mathrm{mL}$, with and without iron and no bLf (control). Analysis occurred in 122 strains of EAEC (60 strains from children with diarrhea and 62 healthy children) previously collected in a previous study of passive surveillance of diarrhea in the Southern Cone Lima. 31 strains of the same method were used for the qualitative study. Results. (A) Qualitative method: 31 strains were evaluated with and without iron. Without iron biofilm formation was $77 \%$ (24/31) in the control group versus $58 \%$ (14/31) with bLf of $0.01 \mathrm{mg} / \mathrm{mL}$ and $4 \%(1 / 31)$ with $1 \mathrm{mg} / \mathrm{ml}$. Iron biofilm formation was $90 \%(28 / 31)$ in the control group versus $55 \%(17 / 31)$ with bLf of $0.01 \mathrm{mg} / \mathrm{mL}$ and $4 \%(1 / 31)$ with $1 \mathrm{mg} / \mathrm{mL}$. (B) Quantitative method: without iron absorbance measured at OD $560 \mathrm{~nm}$ of the control group was $0.7 \pm 0.5$ versus $0.4 \pm 0.3$ with bLf $0.01 \mathrm{mg} / \mathrm{mL}$ and $0.3 \pm 0.2$ with bLf of $1 \mathrm{mg} / \mathrm{mL}(p<0.0001)$. This decrease in the presence of bLf included iron. Conclusions. bLf tends to decrease the formation of biofilms, showing an inhibitory effect in clinical isolates of EAEC; this effect is not iron-dependent.
\end{abstract}

Key words: Lactoferrin; Enteroaggregative Escherichia coli; Biofilms (source: MeSH/NLM).

\footnotetext{
Facultad de Medicina, Universidad Peruana Cayetano Heredia. Lima, Perú.

School of Public Health, University of Texas. Texas, EE.UU.

Médico cirujano; ${ }^{\mathrm{b}}$ magíster en Microbiología; ${ }^{\mathrm{c}}$ médico infectólogo pediatra.

Recibido: : 17-02-14 Aprobado: 06-08-14
}

Citar como: Coveñas C, Dextre G, Fernandez D, Mosquito S, Ochoa T. Efecto de lactoferrina bovina en la formación de biofilms en cepas clínicas de E. coli enteroagregativa. Rev Peru Med Exp Salud Publica. 2014;31(3):454-60. 


\section{INTRODUCCIÓN}

Uno de los problemas de salud pública más importante en países en vías de desarrollo es la diarrea, la cual es una de las principales causas de morbimortalidad en niños menores de 5 años, afectando de manera importante el crecimiento, el estado nutricional y el desarrollo mental del niño ${ }^{(1-4)}$. Uno de los agentes principales de diarrea es el grupo de las Escherichia coli diarrogénicas, siendo la Escherichia coli enteroagregativa (EAEC) la más prevalente ${ }^{(5)}$. Esta ha sido asociada a diarrea aguda y persistente; también ha sido asociada como agente causal de diarrea en individuos afectados con el virus de inmunodeficiencia adquirida ${ }^{(6)}$. Nuevos estudios reconocen a la EAEC como causante de infecciones del tracto urinario, bacteremia y sepsis ${ }^{(7)}$.

La patogenicidad de la EAEC es compleja ya que estas cepas son heterogéneas. El factor de virulencia más estudiado es el gen aggR, el cual se encarga de regular los factores de virulencia, controla la expresión de los factores de adherencia (con un patrón de ladrillos apilados), proteína dispersina y un largo clúster de genes codificados en el cromosoma de la EAEC ${ }^{(7)}$. Esta bacteria presenta tres estadios en su patogénesis: (a) adherencia a la mucosa intestinal colónica mediante la fimbria adherente agregativa (AAF) y otros factores de adherencia; (b) formación de biofilms debido al aumento de la producción de moco generando así la adherencia de la EAEC a la superficie de los enterocitos, y (c) efectos citotóxicos debidos a la respuesta inflamatoria y a la liberación de toxinas que conducen a la destrucción tanto de las microvellosidades intestinales como la de los enterocitos ${ }^{(6,8)}$.

La lactancia materna se ha identificado como la intervención más efectiva para proteger a los niños menores de 5 años de edad contra las diarreas ${ }^{(9)}$. De los componentes de la leche materna, la lactoferrina es la segunda proteína más abundante; se encuentra en una concentración de $10 \mathrm{mg} / \mathrm{mL}$ en el calostro humano y una concentración de $1 \mathrm{mg} / \mathrm{mL}$ en la leche madura (9). Esta proteína posee dos efectos antimicrobianos: (a) Bacteriostático, por su capacidad de quelar el ión férrico limitando su utilización por las bacterias patógenas que lo requieren para su crecimiento y expresión de sus factores de virulencia. (b) Bactericida, al unirse a las porinas y al lípido $A$ del polisacárido (LPS) presente en la membrana externa de las bacterias Gram negativas generando un aumento en la permeabilidad de esta ocasionando daño a la bacteria ${ }^{(9)}$. Un estudio previo de la EAEC con la cepa prototipo O42 (O44:H18) evidenció que la bLf inhibe el crecimiento en forma dosis-dependiente; la adherencia en las células Hep2; la formación de biofilms; aumenta su aglutinación e induce la liberación y degradación de AAF ${ }^{(9)}$.
El objetivo de este estudio fue determinar el efecto de la bLf en la formación de biofilms en cepas clínicas de EAEC. Como objetivo secundario, determinar si el efecto de bLf en la formación de biofilms es independiente del hierro. Este hallazgo es importante pues la formación de biofilms, como ya se mencionó, es uno de los factores de virulencia más importante de este enteropatógeno.

\section{MATERIALES Y MÉTODOS}

\section{DISEÑO DEL ESTUDIO}

Estudio experimental desarrollado en el Laboratorio de Infectología Pediátrica del Laboratorio de Investigación y Desarrollo y en el Laboratorio de Enfermedades Entéricas y de Nutrición de la Universidad Peruana Cayetano Heredia.

\section{SELECCIÓN DE LA MUESTRA}

Se utilizaron 122 cepas clínicas de EAEC aisladas e identificadas por PCR múltiple a tiempo real buscando la presencia del gen aggR en muestras de un estudio previo: "Estudio de la diarrea causada por coliformes (E.coli) y otras causas en niños menores de dos años de edad en Lima, Perú". Este fue un estudio de vigilancia pasiva de diarrea en el cono sur de Lima, en donde se aisló cepas clínicas de EAEC de un grupo proveniente de niños con diarrea y otro proveniente de niños sanos que estaban colonizados con este patógeno ${ }^{(10)}$. De las 122 cepas que se utilizaron en el método cuantitativo, 60 provinieron de niños con diarrea y 62 de niños sanos. En el caso del método cualitativo, se seleccionaron al azar, solo 31 cepas, para realizar este análisis. Este proyecto se desarrolló en el Laboratorio de Enfermedades Entéricas y Nutricionales del Instituto de Medicina Tropical "Alexander von Humboldt" y en el Laboratorio de Infectología Pediátrica de los Laboratorios de Investigación de Desarrollo.

\section{MATERIALES}

Bacterias: para el estudio se utilizó la cepa prototipo EAEC O42 (O44:H18) como cepa control positivo, E. coli $\mathrm{HB} 101$ como cepa control negativo y 122 cepas clínicas de EAEC almacenadas en el criobanco a $-70{ }^{\circ} \mathrm{C}^{(11)}$.

Lactoferrina bovina: se utilizó bLf de Tatua Nutrionals, Nueva Zelanda. Se empleó la concentración de $1,00 \mathrm{mg} / \mathrm{mL}$, equivalente a la concentración de esta proteína en la leche materna madura. Adicionalmente, se usó una concentración menor de $0,01 \mathrm{mg} / \mathrm{mL}$. 
Hierro: se preparó una solución madre de ion férrico a una concentración de $200 \mathrm{mg} / \mathrm{mL}$ de la cual se partió para realizar los ensayos en una relación de $1 \mathrm{M}$ : $2 \mathrm{M}$, respecto a las concentraciones de la bLf $(0,01 \mathrm{mg} / \mathrm{mL}$ y $1 \mathrm{mg} / \mathrm{mL}$ ). En este estudio se suplementó el medio con hierro para demostrar que la disminución de la formación de biofilms no se debe a su efecto bacteriostático (disminución en el crecimiento bacteriano), si no por otro mecanismo no-dependiente del hierro.

Medio de cultivo: para reactivar las bacterias se usó el medio de cultivo Mc Conkey (Merck). Para los ensayos de formación de biofilms se usaron los medios de cultivo DMEM-HEPES (Hyclone) y caldo de cultivo Luria (Invitrogen).

\section{MÉTODOS}

Reactivación de cepas: las 122 cepas clínicas de EAEC se obtuvieron del criobanco a $-70{ }^{\circ} \mathrm{C}$, luego reactivadas en placas con el medio de cultivo Mc Conkey dejándolas crecer por $18-24 \mathrm{~h}$ a $37{ }^{\circ} \mathrm{C}$. Este procedimiento fue el primer paso para ambos métodos.

Método cualitativo: ensayo de la formación de biofilm. Luego de la reactivación de las 31 cepas elegidas al azar, se cultivó $10 \mu \mathrm{L}$ del caldo de cultivo Luria, que contenía a la cepa, en placas de 24 pocillos con el medio DMEMHEPES, a un $\mathrm{pH} 7,4$, suplementado con $0,4 \%$ de glucosa (1:100 diluciones). Cada pocillo contuvo un cubreobjetos en su base. Luego, se agregó lactoferrina a concentraciones de $1,00 \mathrm{mg} / \mathrm{mL}$ y $0,01 \mathrm{mg} / \mathrm{mL}$ con hierro en una relación de $1 \mathrm{M}: 2 \mathrm{M}$ y se dejó a $37{ }^{\circ} \mathrm{C}$ en una incubadora a $5 \%$ $\mathrm{CO}_{2}$ por cuatro horas. Luego, se retiró el cubreobjetos con la bacteria adherida y se lavó vigorosamente. Posteriormente, se retiró el medio y se fijó con etanol al $95 \%$ por 10 min; luego se añadió cristal violeta al $2 \%$ por 10 min y, finalmente, se lavó con solución salina $(0,9 \% \mathrm{NaCl})$. Se hizo la lectura respectiva mediante microscopio de luz óptica por triplicado ${ }^{(9)}$ (Figura 1).

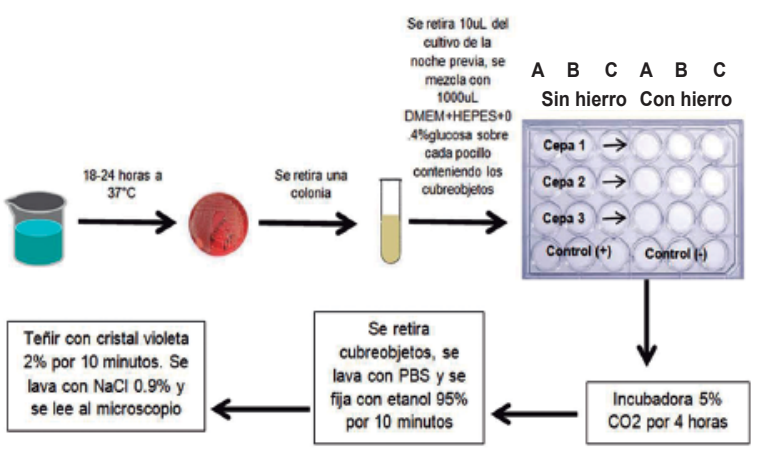

Figura 1. Método cualitativo: ensayo de biofilms (modificado de Ochoa et al., 2008)

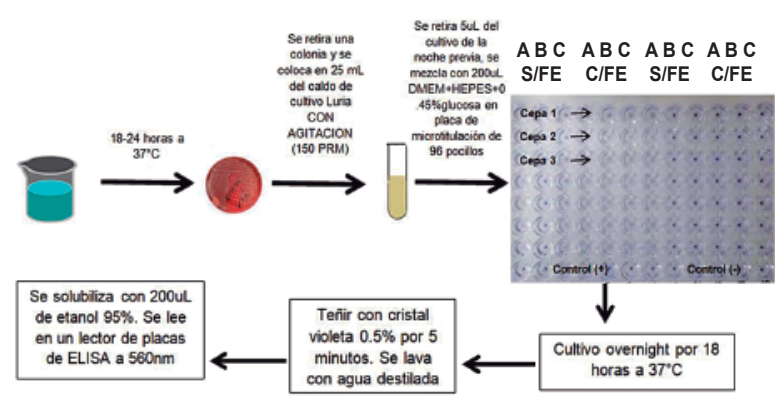

Nota: $A=$ grupo control (bLf $0 \mathrm{mg} / \mathrm{mL}$ ), $B=b L f \quad 0.01 \mathrm{mg} / \mathrm{mL}$ y $C=b L f \quad 1 \mathrm{mg} / \mathrm{mL}$

Figura 2. Método cuantitativo de biopeliculas (modificado de Wakimoto et al., 2004)

Método cuantitativo: ensayo de la formación de biofilms. Luego de la reactivación de las 122 cepas, se retiró una colonia reactivada y se inoculó al medio Luria Broth, y se las cultivó con agitación (150 rpm) por $18 \mathrm{~h}$ a $37^{\circ} \mathrm{C}$. Luego, se transfirió $5 \mathrm{uL}$ del cultivo en $200 \mathrm{uL}$ de medio DMEM-HEPES suplementado con $0,45 \%$ de glucosa, en una placa de ELISA de 96 pocillos de fondo plano. Simultáneamente, se realizaron dos intervenciones: a) se agregó bLf a concentraciones de 1,00 mg/ $\mathrm{mL}$ y $0,01 \mathrm{mg} / \mathrm{mL}$ sin hierro y b) se agregó bLf a concentraciones de $1,00 \mathrm{mg} / \mathrm{mL}$ y $0,01 \mathrm{mg} / \mathrm{mL}$ con hierro, en una relación de $1 \mathrm{M}$ : $2 \mathrm{M}$, con respecto a las concentraciones de la bLf. Esta mezcla se cultivó por $18 \mathrm{~h}$ a $37{ }^{\circ} \mathrm{C}$. Luego, se retiró el medio de todos los pocillos, se tiñó con cristal violeta a $0,5 \%$ por cinco minutos y se realizó el lavado con agua destilada. El biofilm fue cuantificado después de la adición de $200 \mu \mathrm{L}$ de etanol al $95 \%$ por lector de ELISA a $560 \mathrm{~nm}$. La cepa EAEC 042 se utilizó como control positivo y la E. coli HB101 como control negativo ${ }^{(12)}$ (Figura 2).

\section{DEFINICIÓN DE VARIABLES}

Se utilizaron tres tipos de variables: (a) El hierro en una relación de $1 \mathrm{M}: 2 \mathrm{M}$, con respecto a la concentración de bLf; y bLf a concentraciones de 0,01 $\mathrm{mg} / \mathrm{mL}$, $1 \mathrm{mg} / \mathrm{mL}$ y grupo control como variables independientes; (b) La formación de biofilms como variable dependiente definida como ausencia o presencia de la misma, y (c) Las cepas como variables controladas.

\section{ANÁLISIS DE DATOS}

Los datos se almacenaron y procesaron en una base en el programa Excel. Para valorar la medición de la formación de biofilms por el método cuantitativo se obtuvo como nuevo punto de corte de la absorbancia a un OD de $560 \mathrm{~nm}$ a 0,581, obtenido a partir de la absorbancia promedio de la cepa control negativo E.coli 
HB101. Todas las absorbancias medidas en este estudio mayores a 0,581 se consideraron como positivas para la formación de biofilms, mientras que las que estaban por debajo de este punto de corte se consideraron negativas. Los datos de las variables cuantitativas continuas se analizaron con la prueba $\mathrm{T}$ de Student para comparar las medias de la absorbancias entre los grupos, presentando el valor de la media +/- error estándar y se reportó el valor de $p$. Para las variables cualitativas se utilizó la prueba estadística chi-cuadrado, comparando la variable de formación de biofilms versus las diferentes concentraciones de bLf.

\section{RESULTADOS}

\section{MÉTODO CUALITATIVO}

Para la formación de biofilms, se trabajó con 31 cepas de EAEC, a las que se les expuso a dos situaciones: sin y con hierro. En ausencia de hierro la formación de biofilms fue $77 \%(24 / 31)$ del grupo control versus 58\% (14/31) a bLf de $0,01 \mathrm{mg} / \mathrm{mL}$ versus $4 \%(1 / 31)$ a $1 \mathrm{mg} / \mathrm{mL}$. En presencia de hierro la formación de biofilms fue 90\% (28/31) del grupo control versus $55 \%$ (17/31) a bLf de $0,01 \mathrm{mg} / \mathrm{mL}$ versus $4 \%(1 / 31)$ a $1 \mathrm{mg} / \mathrm{mL}$ (Figura 3 ).

\section{MÉTODO CUANTITATIVO}

Para la formación de biofilms se analizó la media de las absorbancias, desviación estándar por medio de la prueba T de Student; comparando los siguientes grupos: (a) Cepas sin hierro, la absorbancia medida a OD $560 \mathrm{~nm}$ del grupo control fue $0,7 \pm 0,5$ versus $0,4 \pm$ 0,3 con bLf $0,01 \mathrm{mg} / \mathrm{mL}$ y 0,3 $\pm 0,2$ con bLf de $1 \mathrm{mg} / \mathrm{mL}$ $(p<0,001)$. (b) Cepas con hierro, la absorbancia medida a OD $560 \mathrm{~nm}$ del grupo control fue $0,7 \pm 0,5$ versus 0,5 $\pm 0,4$ con bLf $0,01 \mathrm{mg} / \mathrm{mL}(p<0,002)$, y $0,7 \pm 0,5$ versus $0,4 \pm 0,3$ con bLf de $1 \mathrm{mg} / \mathrm{mL}(p<0,001)$ (Figura 4). Se consideró positiva la formación de biofilms, cuando la absorbancia medida en el espectrofotómetro a un OD de $560 \mathrm{~nm}$ fue mayor a 0,581. En este método se realizaron dos intervenciones: (a) Cepas trabajadas sin hierro, el grupo control formó biofilms en 52\% (64/122), bLf de $0,01 \mathrm{mg} / \mathrm{mL}$ en $19 \%(23 / 122)$ y bLf de $1 \mathrm{mg} / \mathrm{mL}$ en $8 \%$ (23/122); y (b) Cepas trabajadas con hierro, el grupo control formó biofilms en $47 \%$ (57/122), bLf de $0,01 \mathrm{mg} / \mathrm{mL}$ en $31 \%$ (38/122) y bLf de $1 \mathrm{mg} / \mathrm{mL}$ en $25 \%$ (31/122).

Este efecto se evidenció también con la prueba estadística chi-cuadrado teniendo como variables a la formación de biofilms y la exposición a la bLf a concentraciones de $0,01 \mathrm{mg} / \mathrm{mL}$ y $1 \mathrm{mg} / \mathrm{mL}$ con y $\sin$ hierro. Se compararon los siguientes grupos: (a) Cepas sin hierro del grupo control versus bLf $0,01 \mathrm{mg} / \mathrm{mL}$; grupo control versus bLf $1 \mathrm{mg} / \mathrm{mL}$ y; bLf $0,01 \mathrm{mg} / \mathrm{mL}$ versus bLf $1 \mathrm{mg} / \mathrm{mL}$, obteniéndose en los tres grupos una

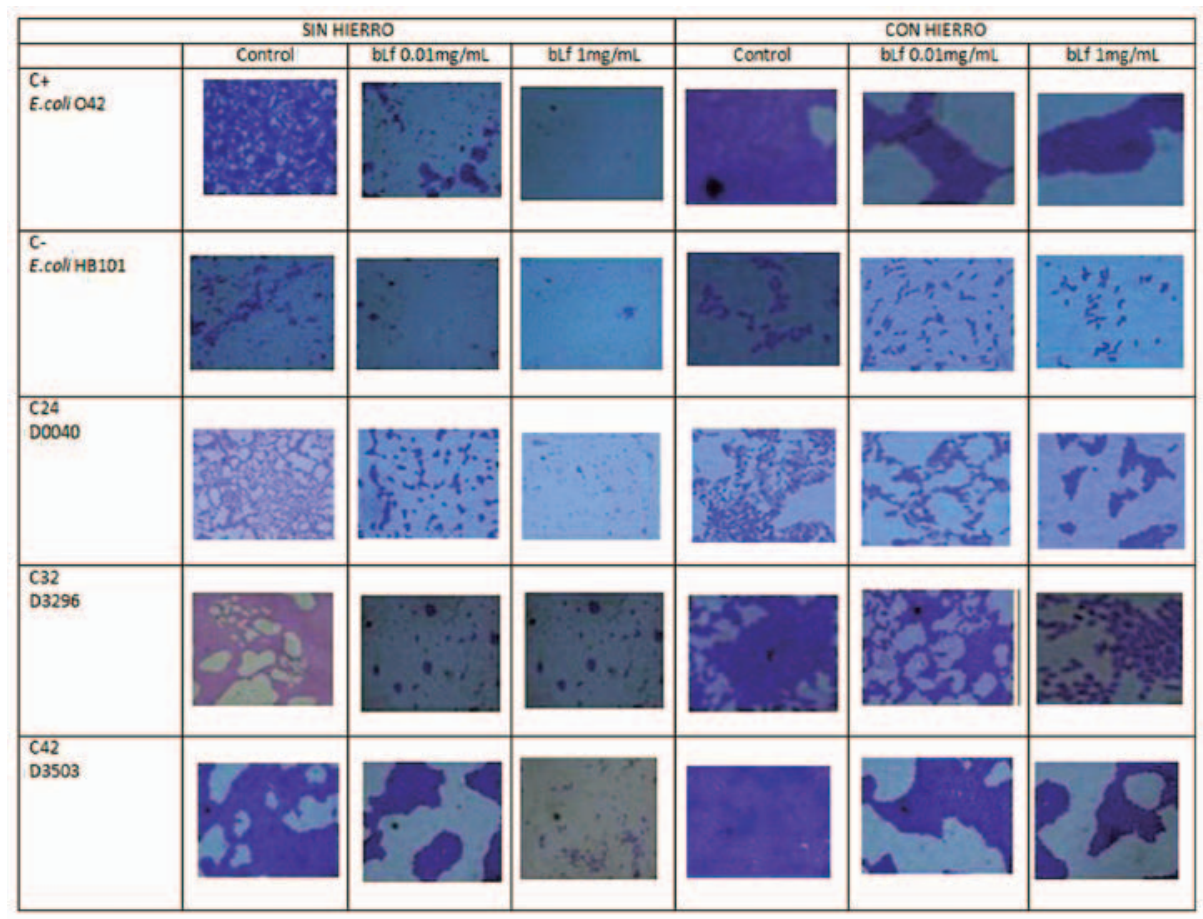

Figura 3. Efecto de la Lactoferria bovina en la formación de biofilms (método cualitativo). Se muestra la formación de biofilms de las cepas sin exposición a Lactoferrina bovina, con y sin hierro; y el efecto de la Lactoferrina bovina a 0,01 mg/mL y $1 \mathrm{mg} / \mathrm{mL}$, con y sin hierro 


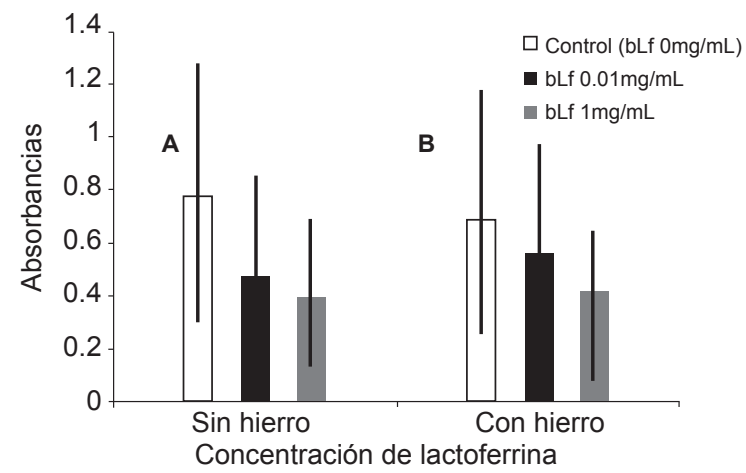

Figura 4. Efecto de la lactoferrina bovina (bLf) en la formación de biofilms medido mediante las medias de las absorbancias. Se compararon las medias de las absorbancias de la formación de biofilms de EAEC sin hierro (A) y con hierro (B) frente a dos situaciones: Grupo control versus bLf $0,01 \mathrm{mg} / \mathrm{mL}$ y grupo control versus bLf $1 \mathrm{mg} / \mathrm{mL}$. La bLf disminuyó la absorbancia cuando fueron expuestas a ésta, incluso en presencia de hierro

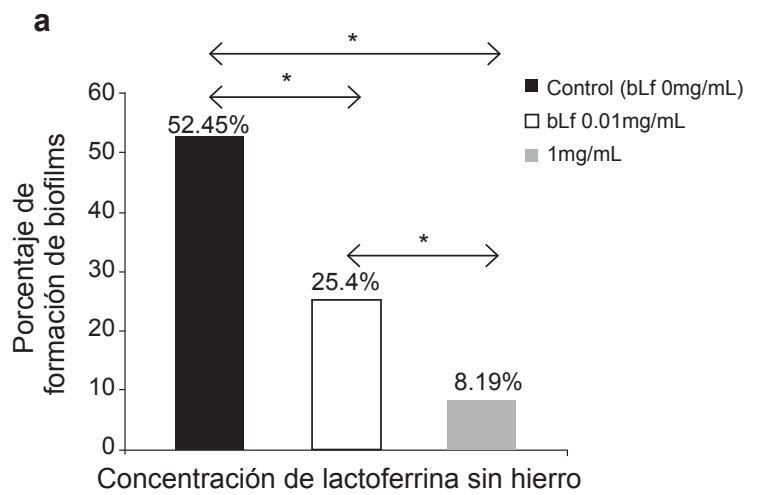

b

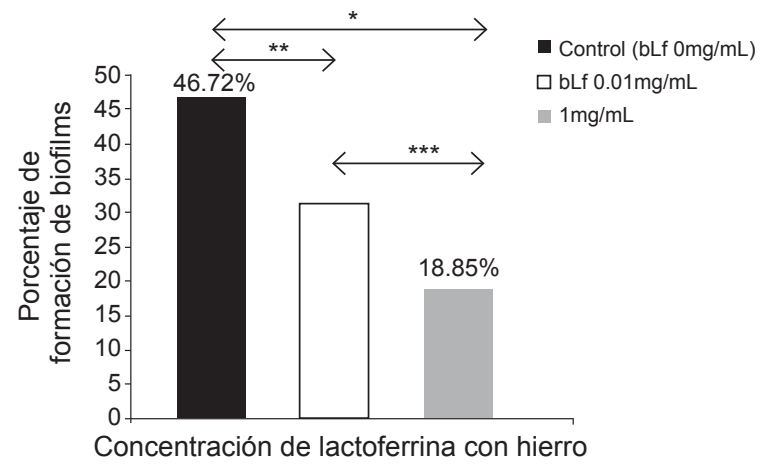

Figura 5. Efecto de lactoferrina bovina (bLf) a concentraciones de $0,01 \mathrm{mg} / \mathrm{mL}$ y $1 \mathrm{mg} / \mathrm{mL}$ con y sin hierro en la formación de biofilms representado en porcentajes. (a) Al comparar las sin hierro entre el grupo control versus bLf $0,01 \mathrm{mg} / \mathrm{mL}$, grupo control versus bLf $1 \mathrm{mg} / \mathrm{mL}$ y bLf $0,01 \mathrm{mg} / \mathrm{mL}$ versus bLf $1 \mathrm{mg} / \mathrm{mL}\left({ }^{*} p<0,001\right)$. (b) Al ser las mismas cepas expuestas a hierro entre el grupo control versus bLf $0,01 \mathrm{mg} / \mathrm{mL}\left({ }^{* *} p<0,01\right)$, grupo control versus bLf $1 \mathrm{mg} / \mathrm{mL}\left({ }^{*} p<0,001\right)$ y bLf $0,01 \mathrm{mg} / \mathrm{mL}$ versus bLf $1 \mathrm{mg} / \mathrm{mL}$ $\left({ }^{* * *} p<0,05\right)$

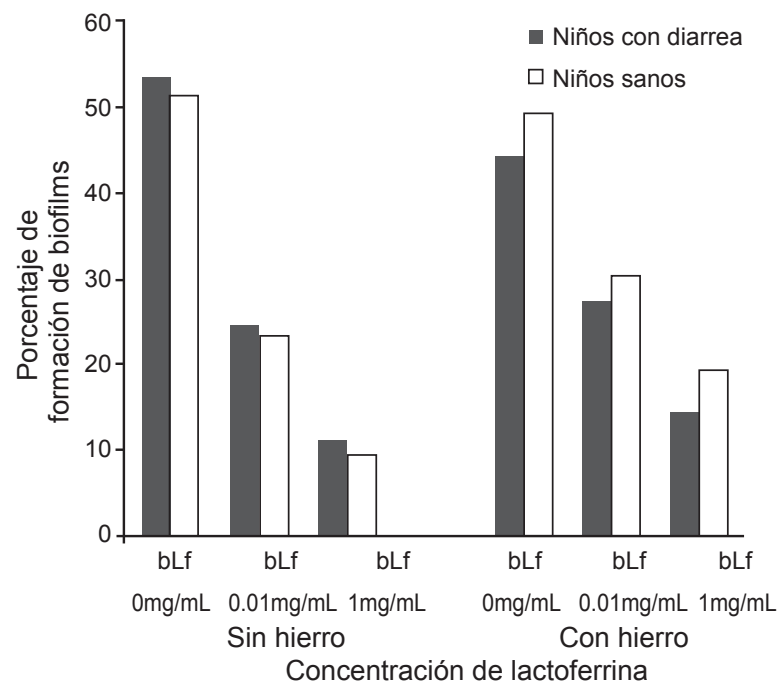

Figura 6. Comparación de la formación de biofilms en niños con diarrea y niños sanos expuestos y no a la lactoferrina bovina a concentraciones de $0,01 \mathrm{mg} / \mathrm{mL}$ y $1 \mathrm{mg} / \mathrm{mL}$. Al comparar la formación de biofilms en ambos grupos no se observó una relación estadísticamente significativa.

disminución en la formación de biofilms estadísticamente significativa $(p<0,001)$ (Figura 5-A). (b) Cepas con hierro del grupo control versus bLf $0,01 \mathrm{mg} / \mathrm{mL}$; grupo control versus bLf $1 \mathrm{mg} / \mathrm{mL}$ y bLf $0,01 \mathrm{mg} / \mathrm{mL}$ versus bLf $1 \mathrm{mg} / \mathrm{mL}$, obteniéndose en los tres grupos un efecto similar a las cepas trabajadas sin hierro: $p<0,01, p<0,001$ y $p<0,05$ respectivamente (Figura 5B).

Comparando los datos, dependiendo si la cepa pertenecía a un niño con diarrea (caso) o niño sano (control) para evaluar la formación de biofilms, a diferentes concentraciones de lactoferrina, no se muestra una relación significativa (Figura 6).

\section{DISCUSIÓN}

Se ha demostrado que la lactoferrina tiene actividad antimicrobiana frente a diferentes patógenos ${ }^{(13,14)}$. Esta actividad está caracterizada por su efecto bacteriostático, al quelar el hierro, y su efecto bactericida al unirse directamente a la célula generando un incremento de la permeabilidad de la membrana ${ }^{(15)}$. Además, tiene otras actividades antibacterianas que se relacionan con su efecto en el desarrollo y formación de biofilms, adhesión bacteriana y colonización, invasión intracelular y apoptosis de las células infectadas ${ }^{(16)}$. Así mismo, se ha estudiado la importancia de la formación de biofilms como factor de virulencia causante de infecciones agudas (diarreas, infecciones del tracto urinario), 
infecciones crónicas, como mecanismo de resistencia bacteriana a los antimicrobianos y el crecimiento de estos en los dispositivos médicos e implantes ${ }^{(7)}$.

Los efectos mencionados de la lactoferrina han sido estudiados en diversos patotipos de $E$. coli diarrogénicas, la importancia del estudio en EAEC radica en el ser el agente aislado con más frecuencia en el sector pediátrico con enfermedad diarreica en nuestro medio ${ }^{(5)}$. El efecto de la lactoferrina sobre la formación de biofilms ha sido estudiado en cepas prototipos de EAEC (O42) en células Hep - 2; sin embargo, este efecto no ha sido estudiado en cepas clínicas de EAEC. Este es el primer estudio, a nuestro entender, donde se describe el efecto de la bLf en cepas clínicas de EAEC obtenidas de niños menores de 2 años. La evaluación del efecto de la lactoferrina en la formación de biofilms se midió utilizando dos métodos: uno cualitativo, que permite visualizar el acúmulo de bacterias unidas al plástico, y uno cuantitativo, que permite medir la cantidad de biofilms de manera indirecta, al medir la cantidad de colorante que se unió a las bacterias adheridas al pocillo de la placa ${ }^{(9)}$. En el método cualitativo se observó que las cepas expuestas a bLf disminuyeron la formación de biofilms incluso a bajas concentraciones de $0,01 \mathrm{mg} /$ $\mathrm{mL}$ al igual que el estudio realizado en cepas prototipos de EAEC ${ }^{(9)}$. El método cuantitativo utilizado en este estudio para la medición de la formación de biofilms fue elegido por presentar una sensibilidad del $100 \%$ y especificidad del $99 \%$ con respecto a otros métodos de estudio ${ }^{(17)}$. Se obtuvo que hay una inhibición y disminución en la formación de biofilms estadísticamente significativa al exponer los biofilms a bLf a concentraciones de $0,01 \mathrm{mg} / \mathrm{mL}$ y $1 \mathrm{mg} / \mathrm{mL}$ con y sin hierro, demostrando que su efecto no es hierro-dependiente. Este método de medición de la formación de biofilms no se utilizó en el estudio con cepas prototipo de EAEC por lo que no se pudo comparar dichos resultados ${ }^{(9)}$.

Al comparar el efecto de la bLf de las cepas provenientes de niños con diarrea y niños sanos, no fue significativo ya que ambos grupos formaron e inhibieron biofilms en cantidades similares. Esto puede deberse al rol que cumple el gen de virulencia en su expresividad y penetrancia entre cepas de EAEC, lo que estaría indicando que las cepas de diarrea y control fueron similares en su habilidad de formar biofilms así como en su respuesta a la lactoferrina.

Una de las limitaciones del estudio es que no se hizo la comparación con el método de formación de biofilms en células Hep-2, previamente descritas para la cepa prototipo EAEC. Sin embargo, la importancia de este estudio es que permitirá realizar estudios futuros que evalúen la acción de la bLf en pacientes con infección del tracto urinario, pacientes colonizados por este patógeno, pacientes que van a ser sometidos a procedimientos médicos invasivos como la colocación de catéteres venosos, arteriales, urinarios y prótesis y como tratamiento o factor protector adicional (profilaxis), por la habilidad de la bLf en disminuir la formación de biofilms.

En conclusión, se observa que la bLf ejerce un efecto inhibitorio en la formación de biofilms a concentraciones de $0,01 \mathrm{mg} / \mathrm{mL}$ y $1 \mathrm{mg} / \mathrm{mL}$ en las cepas clínicas de EAEC medido con los métodos cualitativo y cuantitativo. Estudios futuros deberán evaluar mayor número de cepas, dado que existe heterogeneidad en los genes de virulencia en cepas clínicas.

Contribuciones de autoría: TO y SM participaron en la concepción, diseño y redacción del manuscrito. CC, GD y DF participaron en la obtención de resultados, análisis e interpretación de datos y redacción del manuscrito. TO obtuvo el financiamiento. Todos los autores revisaron en forma crítica versiones preliminares del manuscrito y aprobaron la versión final del trabajo.

Conflictos de interés: los autores no declaran conflicto de interés.

Fuentes de financiamiento: este trabajo fue financiado por fuentes propias del investigador principal, Dra. Theresa Ochoa.

\section{REFERENCIAS BIBLIOGRÁFICAS}

1. Bryce J, Boschi-Pinto C, Shibuya K, Black RE; WHO Child Health Epidemiology Reference Group. WHO estimates of the causes of death in children. Lancet. 2005 Mar 26-Apr 1;365(9465):1147-52.

2. Boschi-Pinto C, Velebit L, Shibuya K. Estimating child mortality due to diarrheal in developing countries. Bull World Health Organ. 2008 Sep;86(9):710-7.

3. Lima AA, Moore SR, Barboza MS Jr, Soares AM, Schleupner MA, Newman $\mathrm{RD}$, et al. Persistent diarrhea signals a critical period of increased diarrhea burdens and nutritional shortfalls: a prospective cohort study among children in northeastern Brazil. J Infect Dis. 2000 May;181(5):1643-51.

4. Berkman DS, Lescano AG, Gilman RH, Lopez SL, Black MM. Effects of stunting, diarrhoeal disease, and parasitic infection during infancy on cognition in late childhood: a 
follow-up study. Lancet. 2002 Feb 16;359(9306):564-71.

5. Ochoa T, Mercado E, Durand D, Rivera F, Mosquito S Contreras C, et al. Frecuencia y patotipos de Escherichia coli diarrogénica en niños peruanos con y sin diarrea. Rev Peru Med Exp Salud Publica. 2011;28(1):13-20.

6. Weintraub A. Enteroaggregative Escherichia coli: epidemiology, virulence and detection. J Med Microbiol. 2007 Jan;56(Pt 1):4-8.

7. HerzogK, Engeler Dusel J, Hugentobler M, Beutin L, Sägesser G, Stephan R, et al. Diarrheagenic enteroaggregative Escherichia coli causing urinary tract infection and bacteremia leading to sepsis. Infection. 2014 Apr;42(2):4414. doi: $10.1007 / \mathrm{s} 15010-013-0569-x$.

8. Kaur P, Chakraborti A, Asea A. Enteroaggregative Escherichia coli: an emerging enteric food borne pathogen. Interdisciplinary Perspectives on Infectious Diseases. 2010;2010:1-10. doi: $10.1155 / 2010 / 254159$.

9. Ochoa TJ, Brown EL, Guion CE, Chen JZ, McMahon RJ, Cleary TG. Effect of lactoferrin on Enteroaggregative E. coli (EAEC). Biochem Cell Biol. 2006 Jun;84(3):369-76.

10. Ochoa TJ, Ecker L, Barletta F, Mispireta ML, Gil AI, Contreras C. Age-related susceptibility to infection with diarrheagenic Escherichia coli among infants from Periurban areas in Lima, Peru. Clin Infect Dis. 2009 Dec 1;49(11):1694702. doi: $10.1086 / 648069$.

11. Guion CE, Ochoa TJ, Walker CM, Barletta F, Cleary TG. Detection of diarrheagenic Escherichia coli by use of melting-curve analysis and real-time multiplex PCR. J Clin Microbiol. 2008 May;46(5):1752-7. doi: 10.1128/ JCM.02341-07.

12. Wakimoto N, Nishi J, Sheikh J, Nataro JP, Sarantuya J, Iwashita M, et al. Quantitative biofilm assay using a microtiter plate to screen for enteroaggregative escherichia coli. Am J Trop Med Hyg. 2004 Nov;71(5):687-90.

13. Gifford JL, Ishida $H$, Vogel HJ. Structural characterization of the interaction of human lactoferrin with calmodulin. PLoS One. 2012;7(12):e51026. doi: 10.1371/ journal.pone.0051026.
14. Baker HM, Baker EN. A structural perspective on lactoferrin function. Biochem Cell Biol. 2012 Jun;90(3):320-8. doi: 10.1139/o11-071.

15. Appelmelk BJ, An YQ, Geerts M, Thijs BG, de Boer HA, MacLaren $\mathrm{DM}$, et al. Lactoferrin is a lipid A binding protein. Infect Immun. 1994 Jun;62(6):2628-32.

16. Orsi N. The antimicrobial activity of lactoferrin: current status and perspectives. Biometals. 2004 Jun;17(3):189-96.

17. Cennimo D, Koo H, Mohamed J, Huang D, Chiang T. Enteroaggregative Escherichia coli: A Review of Trends, Diagnosis, and Treatment. Infect Med. 2007 March;24:100-10.

Correspondencia: Cecilia Coveñas Manrique

Dirección: calle Alonso de Molina 1231, Monterrico, Surco, Lima 33, Perú

Teléfono: +51995667984

Correoelectrónico:cecilia.covenas@upch.pe

\section{Consulte la versión electrónica de la} Revista Peruana de Medicina Experimental y Salud Pública en

\section{www.pubmed.gov}

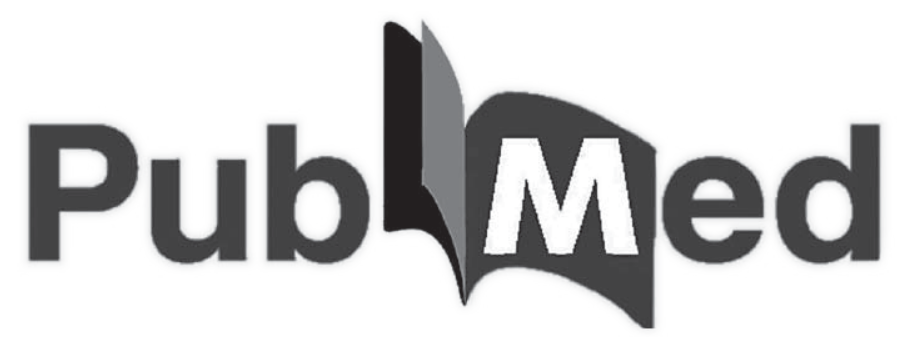

